\title{
The Effects of Ex Ante Informational Social Influence on Web Interface Design Ratings
}

\author{
Daniel S. Soper \\ Department of Information Systems and Decision Sciences \\ California State University, Fullerton \\ dsoper@fullerton.edu
}

\begin{abstract}
Virtually all studies that have hitherto considered factors that influence web interface design ratings have characterized the judge as an independent actor who performs her evaluations in an environment that is free from the effects of direct social influence. In many realworld scenarios, however, the process of assessing a web interface design occurs in a social context, and is hence potentially susceptible to a wide array of direct social influence phenomena. This study focuses on one of these phenomena - informational social influence and demonstrates by means of a controlled, randomized experiment that judges' opinions about a web interface can be easily manipulated. Specifically, it is shown that direct ex ante knowledge of the group opinion significantly influences judges' web interface design ratings, with the degree of influence being, in certain circumstances, positively related to the perceived degree of similarity between the judge and the members of the group. Results are presented and discussed from the perspective of managers who are seeking to obtain unbiased assessments of their organizations' website designs.
\end{abstract}

\section{Introduction}

The human-computer interaction (HCI) literature is replete with research studies that provide insights into the cultural factors and personal traits that influence one's perceptions of the design of a web interface. Studies that examine web interface design assessments, however, typically characterize the person performing the assessment (i.e., the judge) as an independent actor who makes her judgments in an environment that is free of direct social pressure or influence. The problem with this characterization, of course, is that organizational web interface design assessments are rarely carried out in an environment that is entirely free of such direct social pressure or influence. Instead, organizational web interface evaluations are often made by groups (e.g., by web design teams $[1,2]$ or focus groups [3, 4]), especially in situations involving large organizations where creating a high-quality web experience for users or customers is deemed to be of particular or even paramount importance.

Despite the well-established literature on social influence, the extent to which people's views are directly influenced by the group opinion when evaluating web interface designs has attracted very little attention in the HCI research community. Intellectual curiosity notwithstanding, this situation is troubling for two interrelated reasons; namely, (1) because interactions with the Web are now an integral part of daily human life in much of the world, and (2) because websites now commonly serve as the most publically visible face of their underlying organizations. The extent to which a website is well designed can hence directly influence an organization's prospects for success [5], and it is for this reason that managers should be highly interested in ensuring that proposed designs for their organizations' websites are evaluated as accurately and impartially as possible. In this spirit, the current paper reports on the results of a large study aimed at investigating the direct role of ex ante social influence on people's evaluations of the attractiveness of a web interface design. Figure 1 below diagrammatically contrasts this form of social influence with the "No Direct Social Influence" pattern commonly found in the HCI literature. 

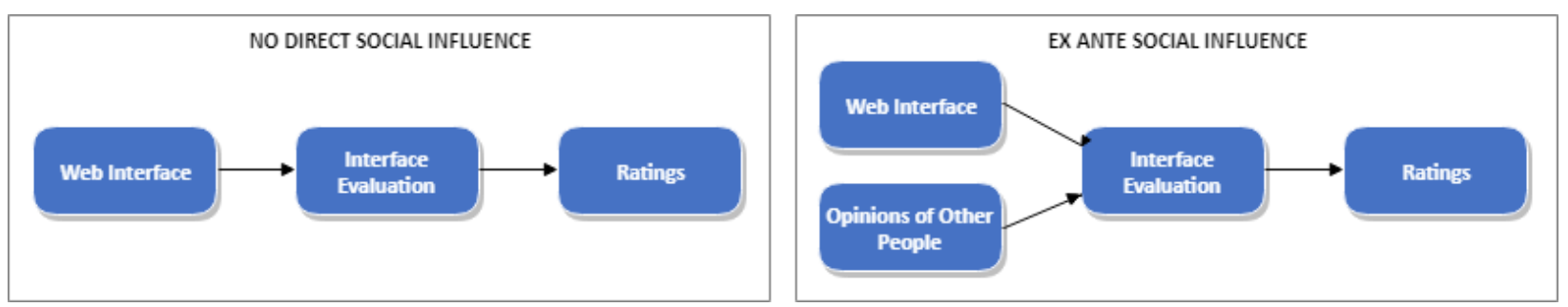

Figure 1. Forms of social influence in the web interface evaluation process.

In the figure above, the "Interface Evaluation" element represents a cognitive process in which the judge considers the interface in question in light of the information that is available to her. Such information includes the interface itself, as well as her past interfacerelated knowledge and experience (i.e., her mental models of web interface design $[5,6])$. Although for purposes of clarity a judge's mental models of web interface design are not depicted in Figure 1, it is important to note that such mental models are imbued with indirect cultural expectations and differences, many of which have formed the basis of nonindividualistic web design research during the past several decades. This paper explicitly differentiates between these kinds of indirect cultural influences and the direct, immediate social influences that can affect one's behavior. In addition to indirect cultural influences, then, a judge may also be immediately aware of what other people think about a web interface, thus raising the specter of interference from direct social influence phenomena during her interface evaluation process. In the case of the "Ex Ante Social Influence" pattern depicted above, the judge is directly and explicitly aware of the opinions of others before she evaluates the interface.

With very few exceptions, all of the HCI research hitherto conducted in the area of web interface design evaluations has fallen within the "No Direct Social Influence" pattern depicted in the figure. The current study seeks to remedy this situation by extending the HCI research on web interface design evaluations into the "Ex Ante Social Influence" pattern shown in Figure 1. Specifically, the current study relies on a controlled, randomized experiment involving three different web interfaces, five interface design characteristics, and more than 850 research subjects to provide insights into the following general research questions:

1. What are the effects of direct ex ante knowledge of the opinions of others on a judge's web interface design ratings?

2. Does the degree of perceived similarity between a judge and the members of a reference group affect the extent to which the judge is influenced by the group's opinion when rating a web interface?

\section{Theoretical Foundations and Research Hypotheses}

The desire to align one's values, beliefs, and attitudes with those of the group exerts a powerful, but often unconscious influence on human behavior, even when the group in question is comprised of complete strangers [7-9]. Humans are, put simply, social creatures who are imbued with a certain innate respect for and desire to belong to the group, and this unconscious regard often drives people not only to defer to the group opinion, but also to behave in a manner that is acceptable to the group with a view toward avoiding social ostracism [10]. Theory from the social psychology literature suggests that this tendency of human beings to defer to the group can manifest itself under several conditions [11]. Specifically, if a person is not confident in her own position or is faced with a difficult or ambiguous situation, she may defer to the group because she believes the group to have superior knowledge or a better understanding of the situation. Put differently, when a person is faced with a challenging task and is not entirely certain of or confident in her answer, she may rely on the opinion of the group as a basis for establishing her own position. This phenomenon in which a person aligns her own beliefs, conclusions, or behaviors with those of the group is known as informational social influence (or alternatively as social proof). Informational social influence has been documented in a wide variety of realworld situations and contexts, and has been observed both across cultures and across time [10].

When considered in the context of web interface design evaluations, the body of theoretical work on informational social influence suggests that individuals may reasonably be expected to behave differently when evaluating a web interface if they are aware of the opinions of others than they otherwise would if the evaluation was being conducted in the absence of social influence. For the "Ex Ante Social Influence" pattern depicted in Figure 1, informational social influence 
theory predicts that if a person has prior knowledge of the opinions of others about a particular web interface, then those opinions can be expected to influence her own ratings of the web interface. This leads to the study's first research hypothesis:

H1: Subjects with direct ex ante knowledge of the average group rating for a web interface design characteristic will assign ratings that are statistically closer to the group's rating than subjects without such ex ante knowledge.

The considerations above notwithstanding, the literature on conformity also contains many studies that have examined the effects of inter-individual differences on social influence phenomena. While gender-based differences in susceptibility to social influence are by no means universal in the conformity literature, a minority of studies have observed the effects of group pressure to be significantly stronger among women [12], making gender an important consideration in any research examining informational social influence. In certain circumstances, age has also been found to be inversely related to social conformity in adults [13], hence making age another important consideration. Together, age and gender have also been identified by past research as the primary features by which people, in the absence of other information, unconsciously judge the degree of similarity between themselves and others [14]. This research has concluded that in the absence of specific knowledge, age and gender are the primary unconscious cues that human beings use when judging how similar they are to others [14]. Intuitively, approximately $50 \%$ of a large group of randomly chosen people would share the subject's gender, while a much smaller percentage would share the subject's age. The least likely combination of all, of course, would be for a randomly chosen person to share both the subject's age and her gender, and in the absence of other information, it is with these people that the subject can be expected to most closely identify. These considerations lead to the study's second research hypothesis:

H2: Among subjects with direct ex ante knowledge of the average group rating for a web interface design characteristic, the distance between the subjects' ratings and those of the group will be inversely related to the degree of similarity between the subject and the group.

\section{Research Design and Methodology}

Insights into the research hypotheses developed in the previous section were gained by means of a controlled, randomized experiment, with the experiment itself being carried out via a purpose-built interactive web application. Inasmuch as the target population for the experiment was English-speaking adult web users, the leading global online advertising firm was engaged to craft a targeted campaign for the purpose of soliciting volunteers for the study. The firm's technology allowed subject recruitment to be explicitly limited to Englishspeaking web users who were at least 18 years old. IP address restrictions were also enforced to ensure that each subject could participate in the experiment only once. Upon agreeing to participate in the experiment, subjects were directed to the web application, and were asked to specify their age and gender. Each subject was then allocated by the web application into one of five experimental groups. In total, data were gathered from 855 subjects, of whom $413(48.3 \%)$ were female and $442(51.7 \%)$ were male. Subjects ranged in age from 18 to 82 years, with the mean age being 33.15 years (std $\mathrm{dev}=12.07)$. These demographic characteristics were observed to be consistent with the overall population of adult web users [15].

As noted above, the experiment was carried out using a custom, web-based software system. As their primary task, subjects were asked to evaluate the characteristics of three web interfaces, each of which was intentionally designed according to the general mental model of web interface design identified by Soper and Mitra [5, 6]. The specific characteristics that were evaluated for each interface were adopted from a pre-validated, five-item subscale that was specifically designed to measure the attractiveness of a web interface [16]. In accordance with the original instrument, subjects in the experiment were asked to respond to the evaluative statements using a sevenpoint, Likert-type scale anchored at $1=$ strongly disagree and $7=$ strongly agree. Minor modifications were made to the wording of the items in order to adapt those items to the context of the current experiment (see Table 1). 


\begin{tabular}{|c|l|}
\hline Original Statement (Aladwania and Palvia 2002) & \multicolumn{1}{|c|}{ Modified Statement Used in Current Experiment } \\
\hline 's website looks attractive. & This website looks attractive. \\
\hline 's website looks organized. & This website looks organized. \\
\hline 's website uses fonts properly. & This website uses fonts properly. \\
\hline 's website uses colors properly. & This website uses colors properly. \\
\hline 's website uses multimedia features properly. & This website uses multimedia features properly. \\
\hline
\end{tabular}

Table 1. Original and modified subscale items.

Each subject was required to evaluate all three web interfaces along just one of the dimensions listed in Table 1 so as to minimize the possibility that her ratings would be contaminated by halo error [17, 18]. The specific design characteristic that each subject was asked to evaluate was determined using iterative assignment, and the order in which the three web interfaces were presented to each subject was randomized to mitigate any ordering or self-generated validity effects $[19,20]$.

The experiment itself utilized a standard betweensubjects (i.e., between-groups) design. Subjects were allocated into one of five groups, which included a baseline group and four experimentally manipulated "treatment" groups. Subjects in the baseline group were simply shown the three interfaces and asked to rate each interface along their assigned dimension. Aside from seeing the interfaces themselves, subjects in the baseline group were provided with no additional information or other cues that might indicate or suggest what other people thought of those interfaces. When aggregated, the responses from subjects in the baseline group were regarded as the true, unadulterated ratings for each interface design characteristic (i.e., ratings obtained in the absence of social influence), and served as the basis against which subject ratings from the treatment groups would be compared.
The rating tasks and experimental process for subjects in the four treatment groups were identical to those of the baseline group, excepting that subjects in the treatment groups were provided with an additional piece of information. To wit, before assigning their ratings, treatment group subjects were provided with experimentally manipulated information about how other people rated the same interface and design characteristic that they themselves were currently considering. Further, the only difference among the four treatment groups was the degree of similarity between these "other people" and the subject herself. Whereas subjects in Treatment Group 1 were simply told that the average group rating with which they were provided came from "other people", subjects in Treatment Groups 2, 3, and 4 were told that the ratings came from other people who were increasingly similar to themselves. A 34-year-old female subject assigned to Treatment Group 2, for example, might be provided with a gender-specific statement such as "The average response given by other women for this question is 2.59 out of 7.00" (emphasis added), while if the subject had been assigned to Treatment Group 4, she might be provided with an age- and gender-specific statement such as "The average response given by other 34-yearold women for this question is 2.59 out of 7.00 ". A more complete illustration of the experiment's betweengroups research design is provided in Figure 2.

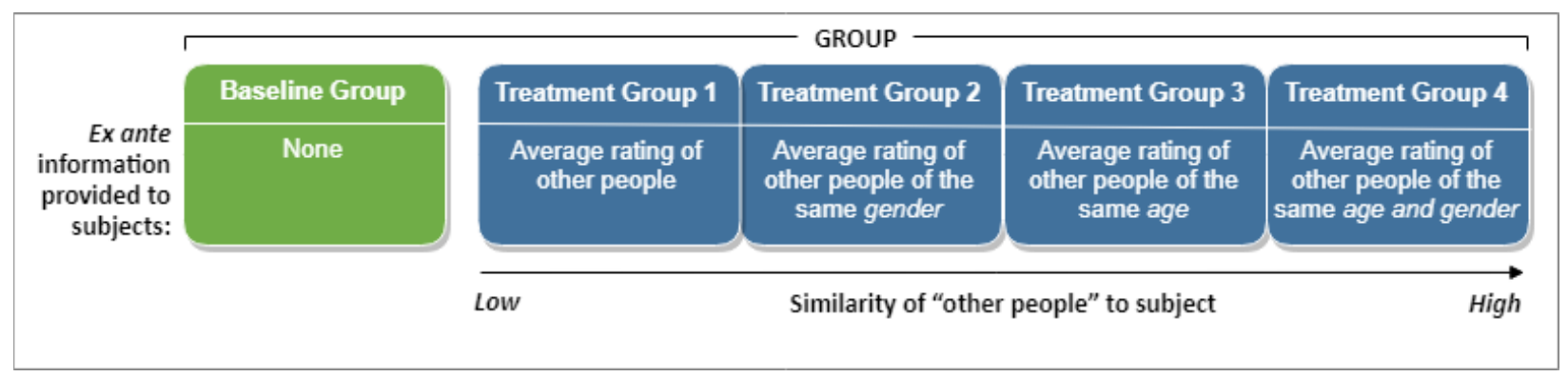

Figure 2. Research design.

With three web interfaces and five interface characteristics, a total of 15 different configurations were possible for each group. For purposes of statistical validity, a minimum of 30 responses were required for each possible configuration (i.e., 450 responses per group). Since each subject provided three responses, the 
preliminary minimum sample size was determined to be 150 subjects per group. Given that the linear models (discussed below) that would be used to evaluate the study's research questions contained nine predictors, a formal a-priori sample size analysis revealed that a minimum of 113 subjects would be required to detect a medium-sized effect $\left(f^{2}\right)$ of 0.15 at a statistical power level of $0.80[21,22]$. The preliminary sample size of 150 subjects per group was thus retained for the experiment. The final dataset was distributed by group according to the values in Table 2 .

\begin{tabular}{|r|c|c|}
\hline \multicolumn{1}{|c|}{ Group } & Subjects & Responses \\
\hline Baseline Group & 150 & 450 \\
\hline Treatment Group 1 (other people) & 177 & 531 \\
\hline Treatment Group 2 (gender) & 176 & 528 \\
\hline Treatment Group 3 (age) & 176 & 528 \\
\hline Treatment Group 4 (age \& gender) & 176 & 528 \\
\hline Total: & $\mathbf{8 5 5}$ & $\mathbf{2 , 5 6 5}$ \\
\hline
\end{tabular}

Table 2. Distribution of subjects and responses by research group.

As noted previously, subjects in the treatment groups were supplied on an ex ante basis with the average rating of other people for the interface design characteristic that they were currently considering. These ratings were not the true ratings given by others, however, but instead were generated with a view toward gaining insight into the study's research hypotheses. Specifically, the artificial ratings supplied to subjects in the treatment groups were statistically derived from the distributions of the baseline ratings. To be more precise, the baseline mean rating and standard deviation for each combination of interface and design characteristic were used to compute the artificial score that was supplied to subjects in the treatment groups, with that artificial score being the value associated with a cumulative probability of 0.05 on the associated baseline rating's normal distribution. For example, the true rating obtained from baseline subjects for the extent to which the third interface used fonts properly was 5.70 (on a 1 to 7 scale), with a standard deviation of 1.32. Applying the cumulative distribution function, it can be readily determined that $95 \%$ of subjects would naturally rate this interface characteristic at 3.53 or above, while only $5 \%$ of subjects would supply a rating lower than 3.53 . In this case, treatment group subjects would be told that the artificially low score of 3.53 was the average rating given by other people when evaluating font usage on that particular interface. Using this approach, it would be statistically unlikely $(p<0.05)$ for a subject in the treatment groups to naturally assign such a low rating to the interface design characteristic that she was evaluating. After controlling for other factors, any statistically significant differences in the ratings given by the baseline and treatment groups could thus be attributed to the effects of the ex ante informational social influence.

Insight into the study's research hypotheses was gained by estimating four linear models, each of which evaluated the extent to which subject ratings in the baseline group differed from one of the four treatment groups. Each linear model was specified such that subject ratings (the dependent variable) were predicted by whether a subject belonged to the baseline group or to the model's associated treatment group, after controlling for the subject's age and gender, and the interface and design characteristic being evaluated (the independent variables). For this purpose, membership in the treatment group, subject gender, and the various interfaces and design characteristics were all appropriately coded using a series of binary dummy variables, yielding a total of nine independent variables. The results of the linear regression analyses are presented and discussed in the following section.

\section{Results}

Initial estimation of the four linear regression models revealed that subject gender did not significantly affect interface design ratings in any of the four treatment conditions. Gender was thus removed as a predictor, and the four linear models were then duly reestimated. After controlling for the effects of a subject's age, the effects of the different web interfaces, and the effects of the different interface design characteristics being evaluated, the artificially manipulated, ex ante information that was provided to subjects about the opinions of others was found to exert a highly significant impact on the subjects' ratings in all four treatment groups $(p<0.001$ 
in all cases). These results are summarized in Figure 3. Since interface characteristics were rated on a 1 to 7 scale, the average difference between the true baseline ratings and those given by subjects in Treatment
Groups 1, 2, 3, and 4 can be quantified as approximately $7.50 \%, 6.28 \%, 8.25 \%$, and $10.28 \%$, respectively.

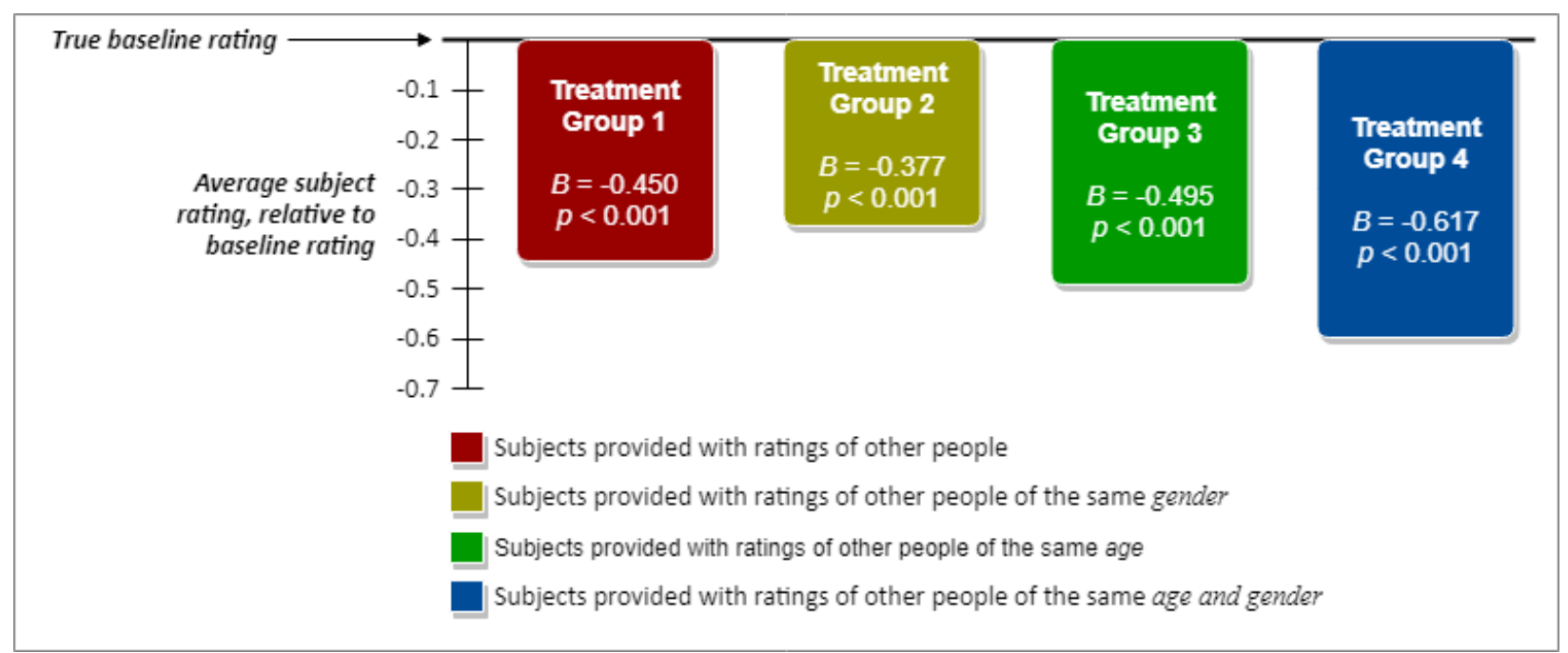

Figure 3. Effects of ex ante informational social influence on subject assessments of web
interface design.

The parameter estimates and associated $p$-values reported in Figure 3 clearly indicate that the responses of subjects in all four treatment groups differed significantly from the corresponding responses of subjects in the baseline group - these results will be discussed in detail in the following section. It was also important, however, to assess the extent to which the responses among the subjects in the various treatment groups differed from each other. Table 3 below thus shows the $F$-values and associated $p$-values that were obtained from a series of one-way analyses of variance (ANOVAs) that were conducted for the purpose of comparing the relative effects of the four different treatment conditions on subjects' web interface ratings.

\begin{tabular}{|c|c|c|c|}
\cline { 2 - 4 } \multicolumn{1}{c|}{} & Treatment Group 1 & Treatment Group 2 & Treatment Group 3 \\
\hline Treatment Group 2 & $\begin{array}{c}\mathrm{F}_{(1,1957)}=248.56 \\
p<0.001\end{array}$ & & \\
\hline Treatment Group 3 & $\begin{array}{c}\mathrm{F}_{(1,1957)}=94.71 \\
p<0.001\end{array}$ & $\begin{array}{c}\mathrm{F}_{(1,1954)}=664.42 \\
p<0.001\end{array}$ & \\
\hline Treatment Group 4 & $\begin{array}{c}\mathrm{F}_{(1,1957)}=1291.43 \\
p<0.001\end{array}$ & $\begin{array}{c}\mathrm{F}_{(1,1954)}=2693.27 \\
p<0.001\end{array}$ & $\begin{array}{c}\mathrm{F}_{(1,1954)}=713.95 \\
p<0.001\end{array}$ \\
\hline
\end{tabular}

\section{Table 3. $F$-values and $p$-values of analyses of variance (ANOVAs) comparing the relative effects of} the four treatment conditions.

The statistics in the table directly compare the magnitudes of the parameter estimates reported in Figure 3, after accounting for their associated standard errors. As shown in the table, the magnitude of the effect of the ex ante information on subject ratings in each treatment group differed significantly from the magnitude of the effect in every other treatment group, thus indicating that the extent to which subjects reacted to the ex ante information was statistically dependent on their perceptions about the people who composed the reference group.

\section{Discussion}

The study's first research hypothesis inquired into whether ex ante knowledge of the opinions of others 
would influence web interface design ratings. As shown in Figure 3, when subjects were provided on an $e x$ ante basis with artificially low ratings that they were told reflected the aggregate opinions of other people, they would, on average, assign a lower rating to the interface design characteristic than baseline subjects. This effect was highly statistically significant in all four treatment groups $(p<0.001)$, indicating that ex ante knowledge of the group's opinion affected subjects' web interface design ratings regardless of the perceived degree of similarity between a subject and the group. Put another way, by simply giving a subject (false) ex ante information about the group opinion, the subject will assign interface design ratings that are much closer to the (false) ratings ostensibly assigned by the group. This finding accords with the predictions of the theoretical work on informational social influence described earlier in the paper, and provides evidence that this behavioral phenomenon is very relevant in the context of web interface design evaluations. Further, given that subjects were perfectly free to choose whatever rating they liked for the various interface design characteristics, the tendency of subjects to align their ratings with those of the group indicates that they were not consciously aware of the fact that their decision-making had been artificially manipulated. From these observations it is possible to conclude not only that people's opinions regarding the design of a web interface can be easily manipulated, but also that ex ante informational social influence can indeed contaminate assessments of web interface design. Hypothesis 1 was therefore fully supported.

The study's second research hypothesis inquired into whether greater perceived similarity between a judge and the members of a reference group would increase the extent to which the judge was influenced by the group's opinion when rating a web interface. Recalling that the similarity between a subject and the reference group increases as one moves from Treatment Group 1 to Treatment Group 4, it is observationally evident from Figure 3 that this hypothesis yielded mixed results. Whereas subjects in Treatment Group 1 (in which a subject had no basis for judging how similar or dissimilar she was to the "other people" with whose ratings she had been provided) assigned interface ratings that were approximately $7.5 \%$ lower than the analogous ratings obtained from the baseline subjects, subjects in Treatment Group 2 (who were given to understand that the group consisted of people of the same gender) exhibited a weaker response by assigning interface ratings that were only approximately $6.3 \%$ lower than the analogous ratings obtained from the baseline subjects. Among Treatment Groups 2, 3, and 4, subjects increasingly aligned their interface ratings with the artificially low ratings of the group when told that the group members were more and more similar to themselves. The results of the analyses of variance reported in Table 3 confirm that the magnitudes of the informational social influence effects did indeed vary significantly among Treatment Groups 2, 3, and 4, indicating that when given cues about the composition of a reference group, greater perceived similarity between a subject and the members of the reference group influences the subject to increasingly align her ratings with the group opinion. Hypothesis 2 was thus partially supported, with the caveat that the hypothesis appears to hold only when subjects have a basis for judging the degree of similarity between themselves and the reference group. In the absence of such information - as was the case with Treatment Group 1 - the unknown composition of the group appears to exert a notable influence whose magnitude exceeds that of a group for which certain characteristics (e.g., gender) are known. This phenomenon definitely deserves further investigation.

When considered together, it is possible to conclude from the results obtained in this study that even when there are no social consequences for disagreeing with the group, people will nevertheless unconsciously seek to align their web interface design assessments with those of the group, particularly when they believe the members of the group to be very similar to themselves.

\section{Implications, Limitations, and Future Research}

The findings reported above have obvious and important implications for managers. In the modern era, a website now commonly serves as an organization's public face, and the design of the organization's website thus has critical consequences for both how the organization is perceived and its prospects for success. Eliminating bias from web interface design assessments should therefore be of particular interest to managers seeking to align their organization's website with the needs and expectations of their users and/or online customers. The results reported in this paper clearly demonstrate that judges' web interface design ratings can be easily manipulated and distorted by the effects of social influence phenomena. As such, managers who desire true, unbiased evaluations or ratings of their organizations' websites are highly recommended to utilize evaluation processes in which those people who are judging the web interface are able to perform their tasks independently and in an environment that is free from the contaminating effects of social influence. 
This practical advice notwithstanding, there is clearly much more to be learned about the role of social phenomena in general - and informational social influence in particular - with respect to assessments of interface design. The results reported here, for example, consider only the effects of ex ante knowledge of the group's opinion on interface design assessments. Are subjects willing to revise their ratings if provided with the group's opinion on an ex post basis? Further, the current study only attempted to discern if ex ante informational social influence would lead subjects to unconsciously lower their web interface ratings. Can ex ante informational social influence also cause ratings to increase? There is also the issue of the actual cognitive mechanism that causes subjects to align their web interface design ratings with those of the group. At the level of unconscious human cognition, could this phenomenon be a manifestation of a more primitive anchoring / adjustment heuristic?

Although questions such as these remain unanswered, informational social influence clearly exerts a powerful impact on a judge's opinion with respect to the design of a user interface, and it seems likely that informational social influence also plays an important role in many other phenomena that lie at the intersection of technology and human behavior. It is therefore hoped that the work reported here will serve as a point of embarkation for a long and fascinating stream of research in this area.

\section{References}

[1] Duyne, D.K.V., Landay, J., and Hong, J.I., The design of sites: patterns, principles, and processes for crafting a customer-centered Web experience, Addison-Wesley Longman Publishing Co., Inc., 2002.

[2] Zaphiris, P., and Kurniawan, S., Human computer interaction research in web design and evaluation, IGI Global, 2007.

[3] Küster, I., and Vila, N., "Successful SME web design through consumer focus groups", International Journal of Quality \& Reliability Management, 28(2), 2011, pp. 132154.

[4] Nielsen, J., "The use and misuse of focus groups", IEEE software, 14(1), 1997, pp. 94-95.

[5] Soper, D.S., and Mitra, S., "The Nature, Antecedents, and Impacts of Visuo-Spatial Mental Models of Web Interface Design", IEEE Access, 4, 2016, pp. 7930-7939.

[6] Soper, D.S., and Mitra, S., "An Inquiry into Mental Models of Web Interface Design", Proceedings of the 19th
Americas Conference on Information Systems (AMCIS), 2013

[7] Asch, S.E., "Effects of group pressure upon the modification and distortion of judgement", in (Guetzkow, H., 'ed.' Groups, leadership and men, Carnegie Press, Pittsburgh, PA, 1951, pp. 222-236.

[8] Asch, S.E., "Studies of independence and conformity: A minority of one against a unanimous majority", Psychological Monographs, 70(9), 1956, pp. 1.

[9] Banerjee, A.V., "A simple model of herd behavior", The Quarterly Journal of Economics, 107(3), 1992, pp. 797-817.

[10] Aronson, E., Wilson, T.D., Akert, R.M., and Sommers, S.R., Social Psychology (9th ed.), Pearson, New York, NY, 2016.

[11] Deutsch, M., and Gerard, H.B., "A study of normative and informational social influences upon individual judgment", The journal of abnormal and social psychology, 51(3), 1955, pp. 629.

[12] Eagly, A.H., "Sex differences in influenceability", Psychological bulletin, 85(1), 1978, pp. 86.

[13] Pasupathi, M., "Age differences in response to conformity pressure for emotional and nonemotional material", Psychology and aging, 14(1), 1999, pp. 170.

[14] Brewer, M.B., and Lui, L.N., "The Primacy of Age and Sex in the Structure of Person Categories", Social Cognition, 7(3), 1989, pp. 262-274.

[15] Pew Research Center, "Internet User Demographics": Pew Research Internet Project Survey, Pew Research, Washington, DC, 2014

[16] Aladwania, A.M., and Palvia, P.C., "Developing and validating an instrument for measuring user-perceived web quality", Information \& Management, 39(6), 2002, pp. 467476.

[17] Soper, D.S., "User Interface Design and the Halo Effect: Some Preliminary Evidence", Proceedings of the 20th Americas Conference on Information Systems (AMCIS), 2014

[18] Soper, D.S., and Piepkorn, F., "Halo Effect Contamination in Assessments of Web Interface Design", Open Journal of Information Systems (OJIS), 5(1), 2018, pp. 1-23.

[19] Chandon, P., Morwitz, V.G., and Reinartz, W.J., "Do Intentions Really Predict Behavior? Self-Generated Validity Effects in Survey Research", Journal of Marketing, 69(2), 2005, pp. 1-14. 
[20] Saris, W.E., and Gallhofer, I.N., Design, Evaluation, and Analysis of Questionnaires for Survey Research, John Wiley \& Sons, Hoboken, NJ, 2007.

[21] Cohen, J., Statistical Power Analysis for the Behavioral Sciences (2nd Edition), Lawrence Earlbaum Associates, Hillsdale, NJ, 1988.

[22] Soper, D.S., A-priori Sample Size Calculator for Multiple Regression [Software].

http://www.danielsoper.com/statcalc, accessed $20 \mathrm{Mar}$ 2019. 